\title{
Characterization of the influence of the casting mould on the surface properties of concrete and on the adhesion of a protective coating
}

\author{
M. Horgnies, P. Willieme, O. Gabet, S. Lombard \& M. Dykman \\ Lafarge Centre de Recherche, St Quentin-Fallavier, France
}

\begin{abstract}
Protective coatings are deposited on concrete to improve aesthetics and to prevent ageing. However, their adhesion on concrete depends on several interlinked parameters. In this study, the surfaces of concrete are characterized according to the process of casting and post-treatment used (sandblasting) by using Scanning Electron Microscopy (SEM), Fourier Transformed-Infrared (FTIR) spectroscopy and profilometry. The surface properties are correlated to the adhesion force of a polyurea (PU) coating. The development of a specific peel test (a strengthened and porous membrane is introduced into the layer of liquid coating before its crosslinking) ensures a reproducible debonding of the coating/concrete system and allows measuring the fracture energy. Moreover, the interface after debonding is analyzed by FT-IR to highlight the presence of concrete/coating residues and to determine the locus of failure. Results underline that the nature of casting mould influences the concrete surface and modifies the adhesion of PU coating. The mould made of polyoxymethylene (POM) induces a micro-tearing of the extreme surface of concrete during demoulding. By increasing the roughness and the open porosity of the concrete surface, this tearing enhances the adhesion of the coating. On the contrary, the smooth concrete surface, induced by the use of a polyvinylchloride (PVC) mould, decreases the anchorage of the coating. Finally, the sandblasting of the surface, by increasing the roughness and the interface area, is an interesting treatment to promote the adhesion of PU coating, whatever the mould used for the casting. Keywords: concrete, coating, roughness, FT-IR, SEM, peel test, adhesion.
\end{abstract}




\section{Introduction}

The staining of concrete could occur due to its specific microstructure that retains the liquid and dust particles. The deposition of a coating is then important to close the surface porosity and protect concrete against acid rains, settlement of algae and lichens...etc $[1,2]$. PU coatings are commonly used due to their high resistance against chemical and mechanical aggressions [3, 4]. However, the surface properties of concrete depend on several interlinked parameters as chemical composition, intrinsic porosity and roughness. The aim of this study concerns the influence of the casting process and post-treatment on the adhesion between PU coating and concrete surface. The influences of the casting conditions on the hardened concrete surface were characterized by SEM, FT-IR and profilometry. Secondly, this study was undertaken to determine if the surface properties of concrete could influence the adhesion of PU coating. Fracture energies were measured by a specific $90^{\circ}$-peel test. This method was retained because it is appropriate to characterize the adhesion of thin films [5-8]. Some publications have already showed the use of strengthened membrane or mesh sheet that were incorporated into the bulk of soft material to characterize [9]. Concerning our system, the introduction of a polymer membrane into the bulk of the coating was necessary to strengthen the system and measure a reproducible adhesion of the PU coating. After the peel tests, the FT-IR analyses of the debonded faces were undertaken to detect the residues of concrete or coating and determine the loci of failure. FT-IR spectroscopy allows detecting organic compounds of coatings $[10,11]$ and several components of concrete [12].

\section{Material and methods}

\subsection{Material}

\subsubsection{Substrates made of hardened concrete}

A high-performance concrete was prepared by mixing $31 \%$ of white Portland cement (CEM I 52.5 PMES from Lafarge), 9\% of limestone filler (DURCAL 1), $7 \%$ of silica fumes (MST), $43.5 \%$ of sand (BE01) and $1.5 \%$ of admixture. A water to cement ratio $(\mathrm{W} / \mathrm{C})$ of 0.26 was used. The samples were prepared by pouring the fresh concrete mixture into horizontal and rectangular formwork $(15 \times 12 \times 1 \mathrm{~cm})$ made of PVC or POM. The concrete samples were removed from their formworks after 18 hours and were stored during 28 days under ambient conditions $\left(25^{\circ} \mathrm{C} ; 50 \%\right.$ relative humidity) to complete their hydration. Some concrete samples were then sandblasted after demoulding (by using a powder of corindon) to increase their roughness. The sandblasted samples were cleaned by air flow to remove the dust before the deposition of coating.

\subsubsection{Coating and conditions of deposition}

The PU coating was composed of $50 \%$ of isocyanates diluted into $45 \%$ of solvent (butyl acetate). A catalyst (dibutylétain laurate, DBTL) was added into the mix to initiate the reaction with water (present in concrete or in atmosphere). 
The isocyanates units reacted with water to produce a polyurea-based film [13]. The coatings were sprayed $\left(120 \mathrm{~g} / \mathrm{m}^{2}\right)$ with air pressure of 3 atmospheres on the concrete surface. The drying period was about 3 days under ambient conditions $\left(25^{\circ} \mathrm{C}, 50 \%\right.$ relative humidity) before peeling.

\subsection{Methods of characterization}

\subsubsection{Scanning electron microscopy (SEM)}

Samples were characterized by using a high-resolution field-effect gun digital scanning electron microscope (SEM FEG Quanta 400 from FEI Company; using an accelerating voltage of $15 \mathrm{keV}$ and a current intensity of $1 \mathrm{nA}$ ). Images of the cross-sections were obtained after being polished.

\subsubsection{Profilometry}

The roughness of concrete samples was measured with a Surftest SJ-201 M mechanical profilometer (Mitutoyo) in order to calculate the arithmetic mean of the profile deviations from the mean line $(\mathrm{Ra})$. The $\mathrm{Ra}$ value was obtained by compiling the arithmetic mean of 5 profiles of $12.5 \mathrm{~mm}$.

\subsubsection{Fourier transform-infrared spectroscopy (FT-IR)}

The FT-IR spectrometer Nicolet iS10 (Thermo Fisher Scientific Inc.) was equipped with a deuterated triglycine sulfate (DTGS) detector and controlled by OMNIC software. The Attenuated Total Reflexion (ATR) mode was mainly used in this study. FT-IR (in ATR mode) characterized the sample over a thickness of a few $\mu \mathrm{m}$. The sampling area analyzed was approximately $1 \mathrm{~mm}^{2}$. The crystal used was made of diamond and 16 scans were routinely recorded over the range $4,000-650 \mathrm{~cm}^{-1}$ with a spectral resolution of $4 \mathrm{~cm}^{-1}$. The background was collected at ambient atmosphere before analyzing each sample. Spectra were corrected with a linear baseline. No specific preparations of the samples of concrete and coating were performed before FT-IR analyses: they were studied just after demoulding or after debonding.

\subsubsection{Specific peel tests of concrete/coating system}

Peel test allows measuring the debonding force $(\mathrm{F})$. According to the peel angle $(\theta)$ and the width of the adhesive coating $(w)$, the fracture energy $(\mathrm{G})$ could be calculated according to [14]:

$$
G=\left(\frac{F}{w}\right)(1-\cos \theta)
$$

In the specific case of $90^{\circ}$ peel angle, $\mathrm{G}$ is equal to the peeling force $(\mathrm{F})$ divided by the width (w) of the adhesive coating. The coating was strengthened by inserting a membrane. The membrane was firstly cut in polyamide 6.6 tissues (Nytex from Dutscher SAS) and deposited on each concrete samples. The coating was directly sprayed on this membrane in order to avoid any air bubble at the interface. Finally, the edges of the membrane were cut to avoid any shear during the debonding. The membrane was flexible but non-stretched under the 
solicitations that occurred during the peel test. The dimensions of each membrane were $200 \mathrm{~mm}$ long, $20 \mathrm{~mm}$ wide, $120 \mu \mathrm{m}$ thick, with an open porosity of $50 \%$ and a mesh opening of $150 \mu \mathrm{m}$. We observed by SEM (Figure 1) a crosssection of the concrete/coating interface in order to describe the system. No mechanical step was used to initiate the crack at the interface. All the $90^{\circ}$-peel tests were performed with a $1000 \mathrm{~N}$ sensor, equipped with a specific mobile table (as detailed by Figure 2). All the peel tests were performed under ambient conditions $\left(25^{\circ} \mathrm{C}, 50 \%\right.$ relative humidity) and by using a constant speed of peel $(0.2 \mathrm{~mm} / \mathrm{s})$.

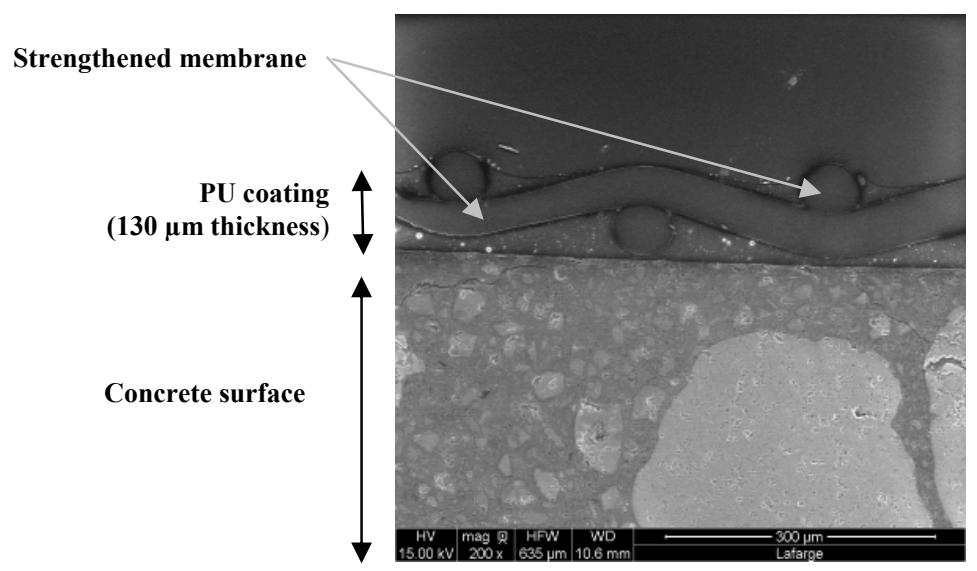

Figure 1: $\quad$ SEM image of a cross-section of the concrete/coating system.

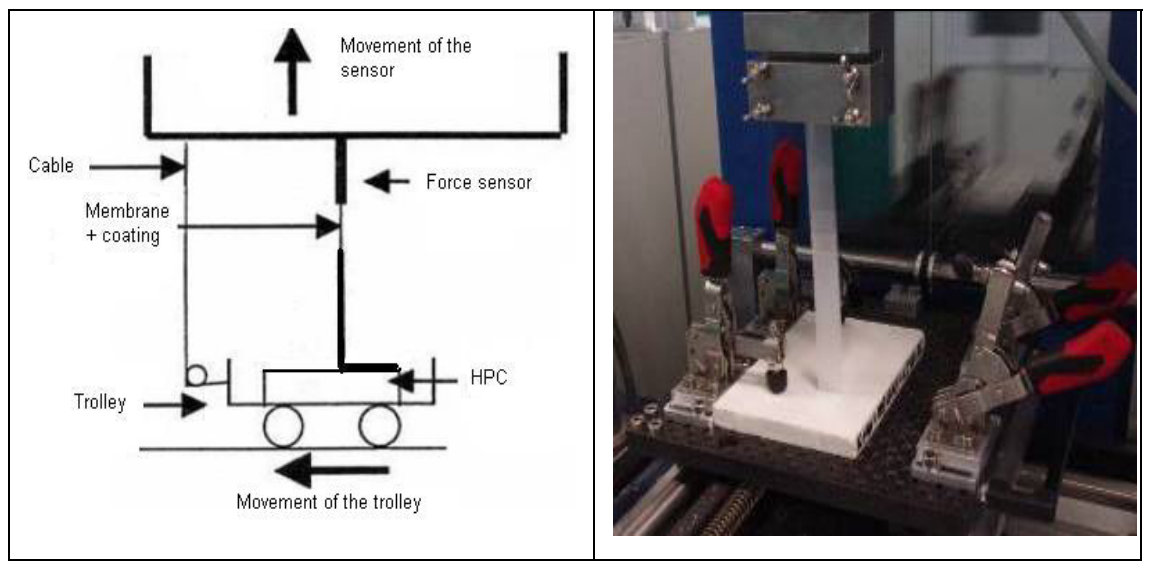

Figure 2: $\quad$ Schema and image of the experimental test of peeling. 


\section{Results}

\subsection{Analyses of the surfaces of reference materials}

\subsubsection{Concrete surfaces according to the nature of the mould}

Table 1 details the IR bands of concrete (demoulded with PVC). Portlandite (at $3640 \mathrm{~cm}^{-1}$ ) and C-S-H*/silica (large band at $1078 \mathrm{~cm}^{-1}$ ) were well detected. Moreover, three strong bands were also assigned to the presence of $\mathrm{CaCO}_{3}$. Their detection confirmed previous studies [12]. Detection of $\mathrm{CaCO}_{3}$ could be due to the carbonation process but also due to the use of limestone filler in concrete mix. As presented by Table 1, concrete demoulded with POM (spectrum not shown) underlines distinct IR bands at 935 and $900 \mathrm{~cm}^{-1}$ that were assigned to alite [15] (a component of the cement before hydration). This FT-IR spectrum showed also peaks at 1092 and $800 \mathrm{~cm}^{-1}$, assigned to Si-O bonds from silica fumes [12]. These silica fumes and alite are usually present into the bulk of concrete sample. Moreover, no IR band of the portlandite $\left(\mathrm{Ca}(\mathrm{OH})_{2}\right)$ was detected.

Table 1: Assignment of FT-IR bands recorded on reference materials.

\begin{tabular}{|c|c|c|c|c|}
\hline Assignment & $\begin{array}{c}\text { FT-IR bands } \\
\left(\mathrm{cm}^{-1}\right)\end{array}$ & $\begin{array}{c}\text { Concrete } \\
(\text { PVC mould })\end{array}$ & $\begin{array}{c}\text { Concrete } \\
(\text { POM mould })\end{array}$ & $\begin{array}{c}\text { PU } \\
\text { coating }\end{array}$ \\
\hline $\mathrm{O}-\mathrm{H} ; \mathrm{Ca}(\mathrm{OH})_{2}$ & 3640 & $\mathrm{X}$ & & \\
\hline $\mathrm{C}=\mathrm{O} ; \mathrm{CaCO}_{3}$ & $1410 ; 872 ; 710$ & $\mathrm{X}$ & $\mathrm{X}$ & \\
\hline $\mathrm{Si}-\mathrm{O} ;$ silicates, $\mathrm{CSH}$ & $1080-970$ & $\mathrm{X}$ & $\mathrm{X}$ & \\
\hline $\mathrm{Si}-\mathrm{O} ; \mathrm{C}_{3} \mathrm{~S}$ & $935 ; 900$ & & $\mathrm{X}$ & \\
\hline $\mathrm{Si}-\mathrm{O} ;$ silica & $797 ; 777$ & $\mathrm{X}$ & $\mathrm{X}$ & \\
\hline $\mathrm{CH}_{2} / \mathrm{CH}_{3} ;$ methyl units & $2850 ; 2950 ; 1450$ & & & $\mathrm{X}$ \\
\hline $\mathrm{N}-\mathrm{H} ;$ urea & 3335 & & & $\mathrm{X}$ \\
\hline $\mathrm{NCO}$ isocyanates & 2270 & & & $\mathrm{X}$ \\
\hline $\mathrm{C}=\mathrm{O} ;$ urea & 1690 & & & $\mathrm{X}$ \\
\hline
\end{tabular}

The concrete samples were also studied by SEM. Concrete demoulded with POM (Figures $3 \mathrm{a}$ and $3 \mathrm{~b}$ ) appears to be rougher than concrete demoulded with PVC (Figures 3c and 3d). The flat topography observed after using PVC mould contrasted with the heterogeneous surface obtained after using a POM mould. These observations confirmed the measurements obtained by profilometry (Table 2): the Ra values of concrete could vary according to the demoulding process. Indeed, the results obtained by SEM suggest that a tearing of the extreme surface of concrete could happen during the removing of the POM mould. This hypothesis could explain why silica fumes were easily observed by SEM (Figure 3b) and why alite was detected by FT-IR spectroscopy (Table 1). 


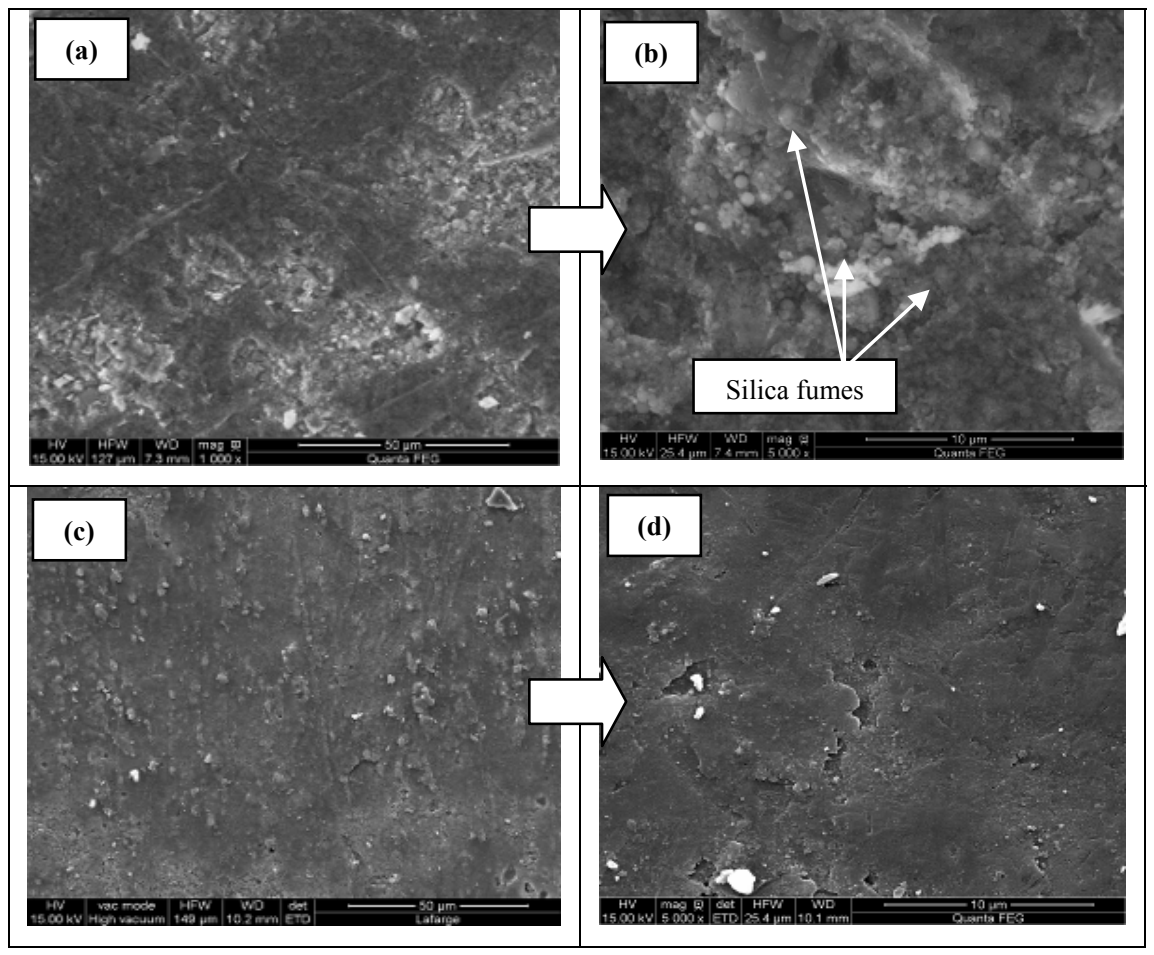

Figure 3: $\quad$ SEM images recorded on concrete samples: $(a, b)$ if POM mould; (c, d) if PVC mould.

Table 2: Roughness of concrete according to the demoulding and posttreatment.

\begin{tabular}{|c|c|c|}
\hline Ra roughness $(\mu \mathrm{m})$ & Concrete (POM mould) & Concrete (PVC mould) \\
\hline Reference & $0.7 \mu \mathrm{m}+/-0.3$ & $0.5 \mu \mathrm{m}+/-0.3$ \\
\hline After sandblasting & $12.2 \mu \mathrm{m}+/-0.4$ & $12.1 \mu \mathrm{m}+/-0.5$ \\
\hline
\end{tabular}

\subsubsection{Concrete surfaces after sandblasting}

Table 2 summarizes the roughness of sandblasted concrete, compared to the one before demoulding. The initial roughness of $0.5-0.7 \mu \mathrm{m}$ range (depending on the nature of mould used) increased to a higher $\mathrm{Ra}$ values of $12 \mu \mathrm{m}$ after sandblasting (whatever the nature of the mould used). SEM images of the sandblasted concrete, presented in Figure 4, could be compared to the ones of the reference concrete samples (Figure 3). The sandblasted surface was rougher than after demoulding. Silica fumes were also detected after sandblasting.

Figure 5 compares FT-IR spectra recorded on concrete (PVC mould) samples before and after sandblasting. The intensity of the bands assigned to the $\mathrm{CaCO}_{3}$ compounds (at 1410, 870 and $710 \mathrm{~cm}^{-1}$ ) decreased after sandblasting while the intensity of peaks of alite (at $930-900 \mathrm{~cm}^{-1}$ ) and silica (at $1100 \mathrm{~cm}^{-1}$ ) increased. 


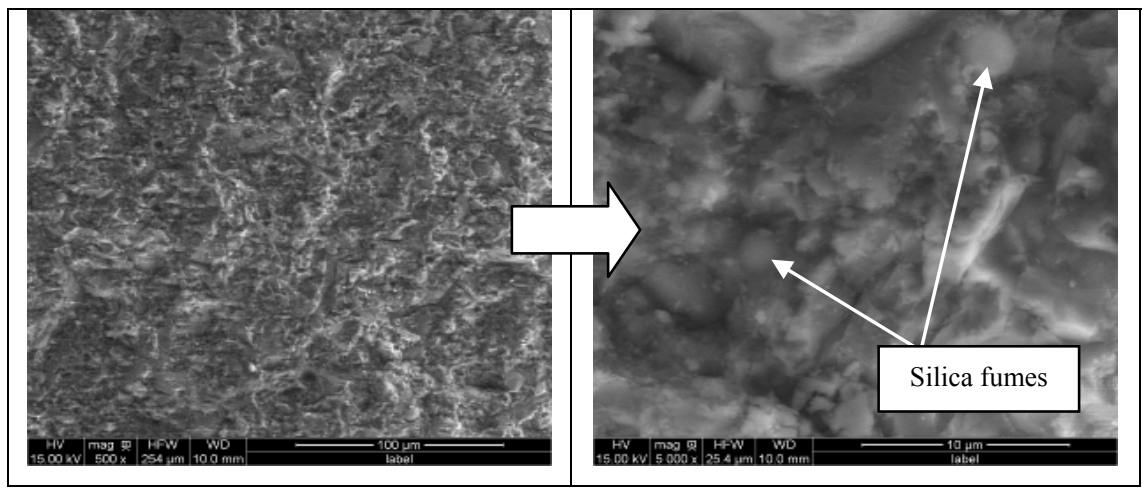

Figure 4: $\quad$ SEM images of concrete (PVC mould) samples after sandblasting.

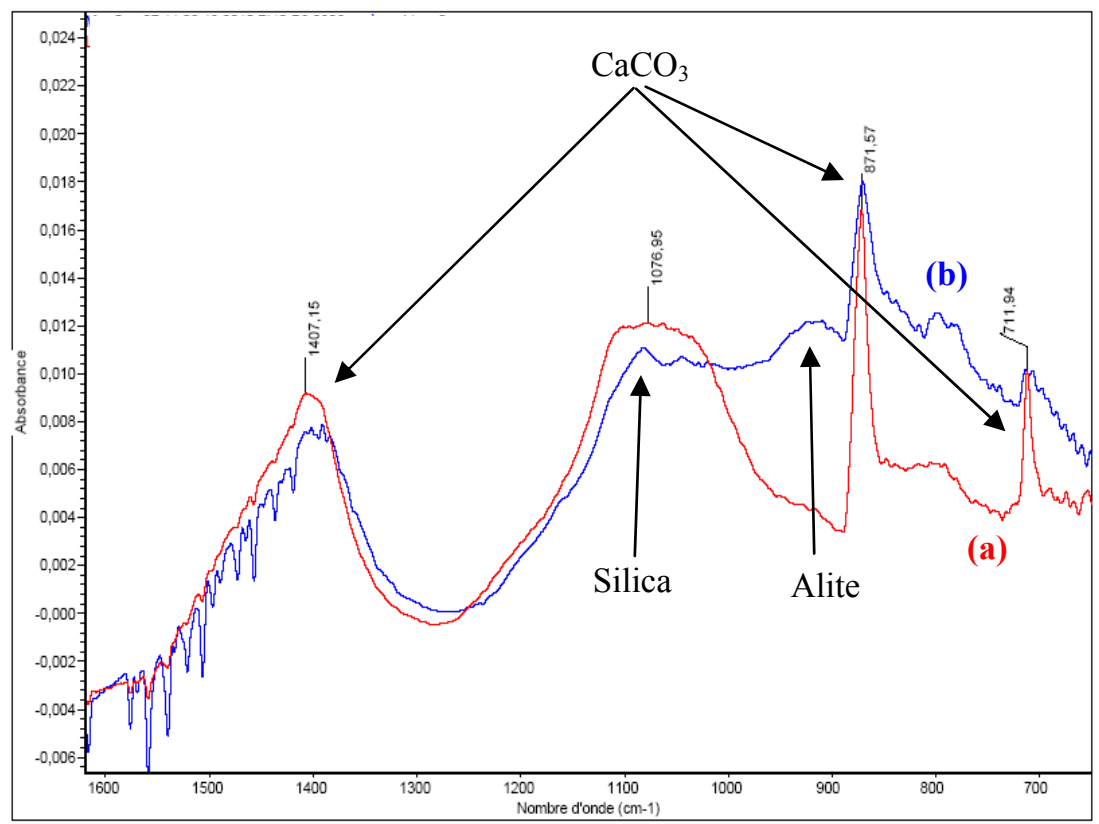

Figure 5: FT-IR spectra of concrete samples (PVC mould): (a) before sandblasting; (b) after sandblasting.

\subsubsection{PU coating with membrane}

FT-IR spectroscopy is known to determine the degree of crosslinking of the isocyanates because a band at $2270 \mathrm{~cm}^{-1}$ characterizes presence of isocyanates units $[16,17]$. In this study, no results of adhesion were linked to the degree of crosslinking of the coating. However, Table 1 underlines other IR bands assigned to the presence of urea units (at 3335 and $1690 \mathrm{~cm}^{-1}$ ). These bands were used to detect the residues of PU coating after peeling. The membrane made of 
polyamide 6.6. was also analyzed by FT-IR in order to assign the reference peaks (amide units at 3300, 3070, 1630 and $1530 \mathrm{~cm}^{-1}$ ). However, these IR bands of the polyamide were never detected at the interface after debonding.

\subsection{Results of peel tests and FT-IR analyses of the interface after debonding}

\subsubsection{Influence of the mould used to cast the concrete}

Figure 6 compares the peel curves obtained during the debonding of PU coating from concrete samples. The adhesion of the coating varied according to the nature of the casting mould.

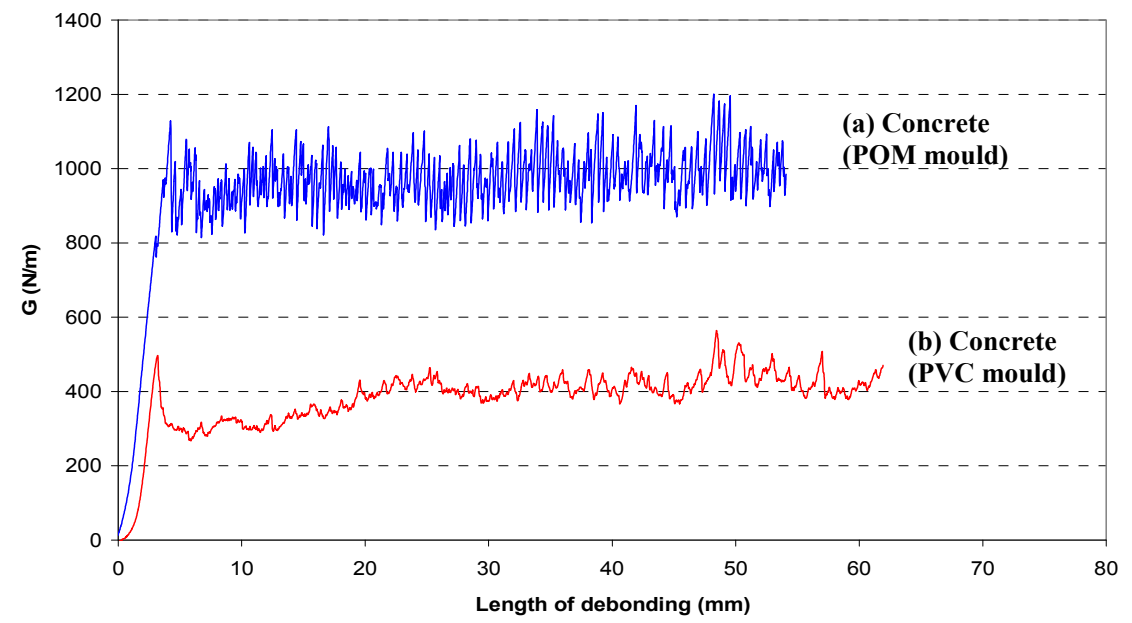

Figure 6: Peel curves of coating recorded on concrete samples: (a, in blue) if POM mould; (b, in red) if PVC mould.

As described by Table 3, the fracture energy measured during the peel of the PU coating from concrete (POM mould) is higher $(1000 \mathrm{~N} / \mathrm{m}+/-150)$ than the one measured during the peel from concrete (PVC mould): $400 \mathrm{~N} / \mathrm{m}+/-50$. Figure 7a presents the FT-IR spectrum recorded on concrete (POM mould) side after peeling: almost all the IR bands were assigned to the residues of coating that covered the entire surface. These results confirm that the high fracture energy was linked to a debonding into the bulk of the coating. It could also be deduced that the adhesion between concrete and coating was better than 1000 $\mathrm{N} / \mathrm{m}$. On the contrary, Figure $7 \mathrm{~b}$ shows FT-IR spectrum of concrete (PVC mould) side after peeling: compounds of concrete (such as $\mathrm{CaCO}_{3}$, silica and portlandite) were mainly detected. Concerning the internal side of coating after peeling from concrete (PVC mould) sample, all the IR bands (spectrum not shown) were assigned to the own components of the coating. No FT-IR bands could be assigned to concrete residues. 
Table 3: Results obtained by peel tests and by FTIR analyses of the interface.

\begin{tabular}{|c|c|c|c|}
\hline Sample & $\begin{array}{c}\text { Post-treatment of concrete } \\
\text { before coating }\end{array}$ & $\begin{array}{c}\text { Fracture } \\
\text { energy }(\mathrm{N} / \mathrm{m})\end{array}$ & $\begin{array}{c}\text { Failure localization deduced } \\
\text { from FTIR analyses }\end{array}$ \\
\hline \multirow{2}{*}{ Concrete/POM } & $/$ & $1000+/-150$ & Inside the PU coating \\
\cline { 2 - 4 } & Sandblasting & $1200+/-100$ & Inside the PU coating \\
\hline \multirow{2}{*}{ Concrete/PVC } & $/$ & $400+/-50$ & At concrete/PU interface \\
\cline { 2 - 4 } & Sandblasting & $1200+/-100$ & Inside the PU coating \\
\hline
\end{tabular}
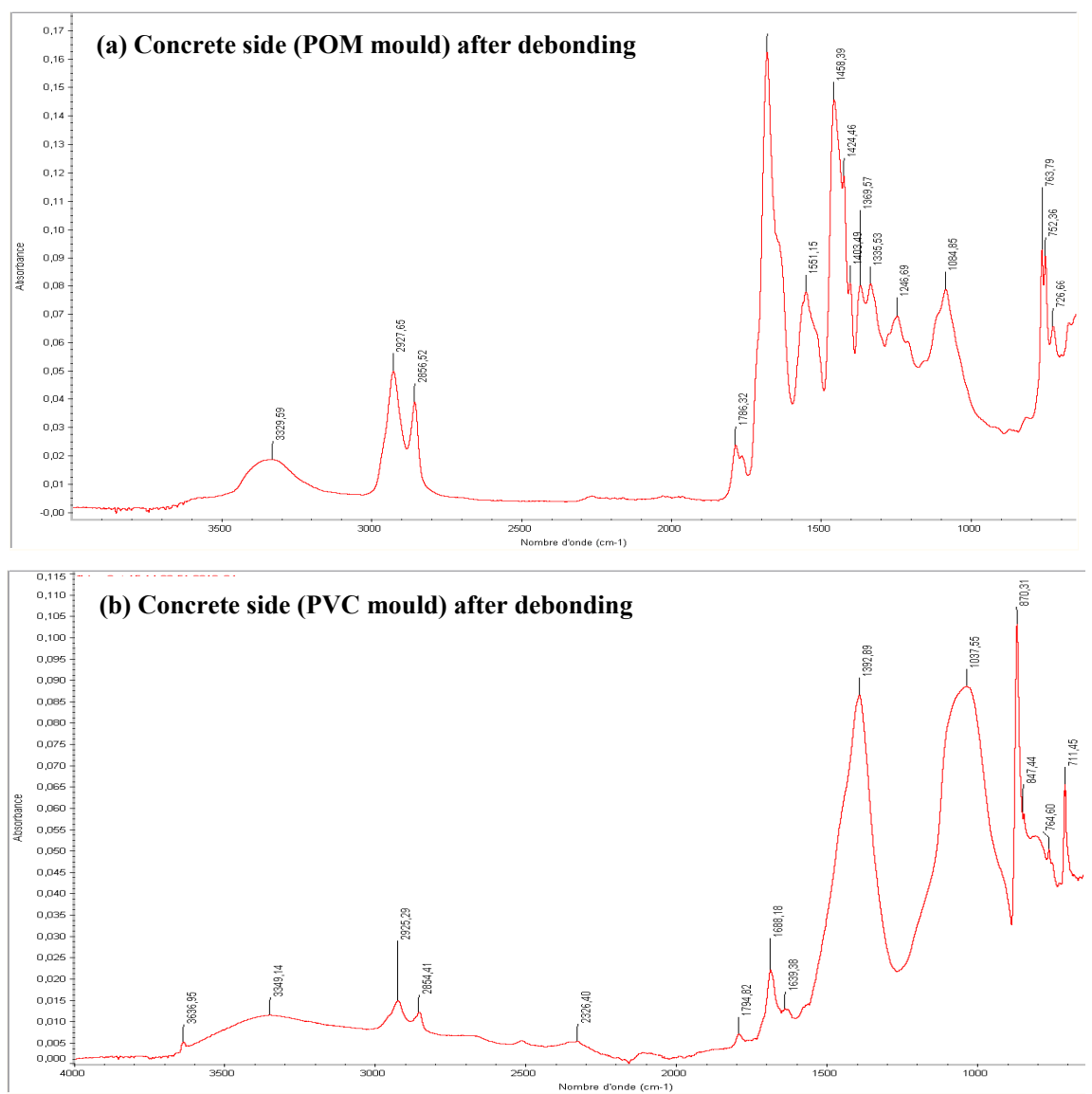

Figure 7: FTIR spectra of concrete sides after peeling: (a) if POM mould; (b) if PVC mould.

These data allow concluding that the debonding occurred at the interface between concrete and coating. The fracture energies and FT-IR analyses of the locus of failure could be correlated to the SEM observations of concrete surface 
before the deposition of the coating. Figure 3 had highlighted that the surface of concrete demoulded with POM was more heterogeneous than concrete demoulded with PVC, which was smoother. We can deduce that the liquid coating (before crosslinking) strongly diffused and anchored into the heterogeneous concrete surface, demoulded with POM. On the contrary, the smooth and close concrete demoulded with PVC did not allow a high mechanical anchorage of the coating.

\subsubsection{Influence of the sandblasting of concrete surface}

The peels tests undertaken on the sandblasted concrete (PVC mould) highlighted high fracture energies (about $1200 \mathrm{~N} / \mathrm{m}$ ) while the peel undertaken on reference concrete (PVC mould) samples induced a low level of adhesion of the PU coating $(350-400 \mathrm{~N} / \mathrm{m})$, as described in Figure 8a. Concerning concrete demoulded with POM, the fracture energies (presented in Figure $8 \mathrm{~b}$ ) did not
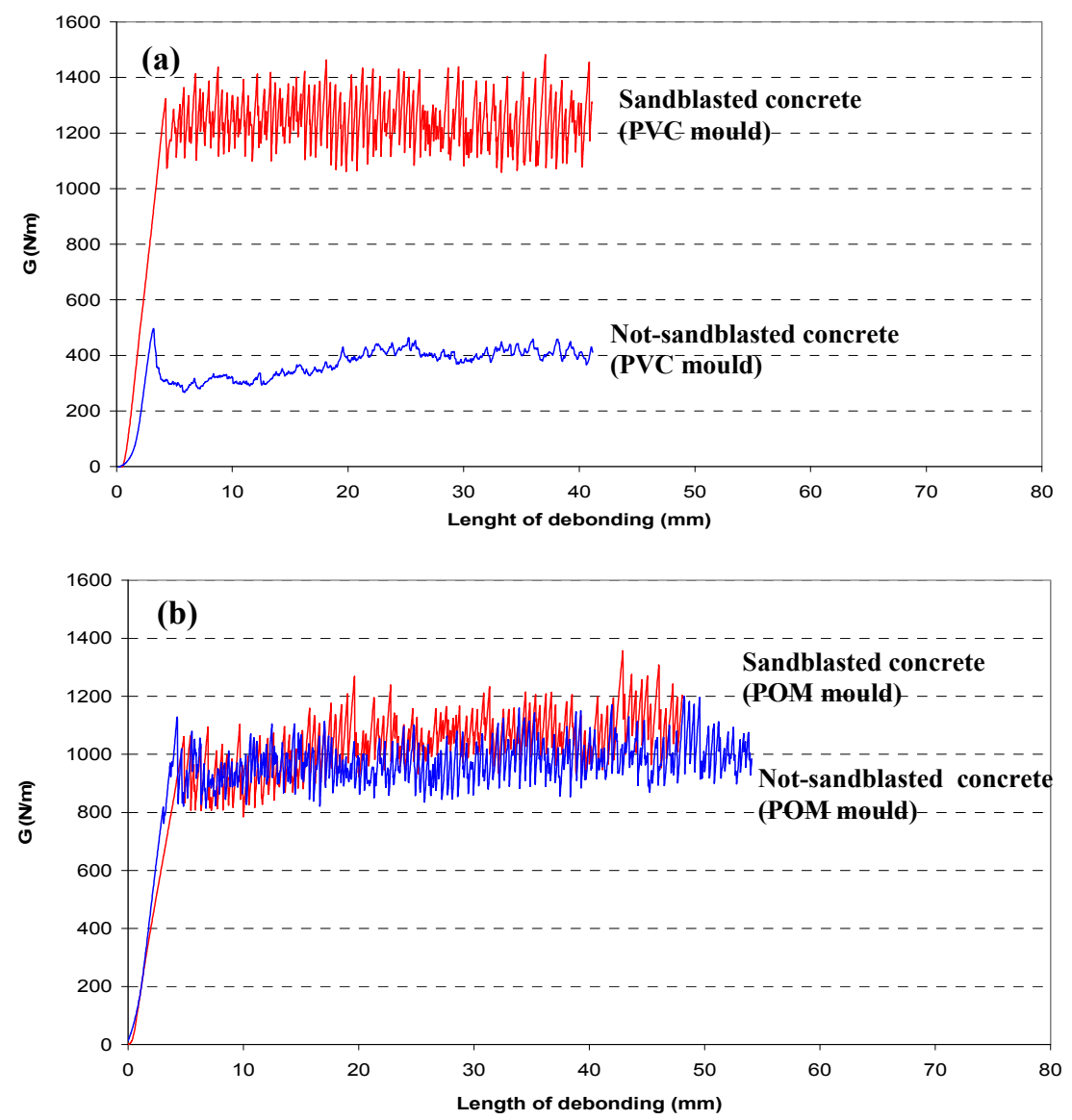

Figure 8: Peel curves of the coating recorded on concrete with or without sandblasting: (a) if PVC mould; (b) if POM mould. 
evolve: they were as high after sandblasting as after demoulding. Thanks to these results, we can conclude that a sandblasting of concrete demoulded with PVC could be interesting to enhance the adhesion of PU coating. As described by SEM images (Figure 4) and values of roughness (Table 2), the open porosity and the roughness of concrete demoulded with PVC were higher after the sandblasting (Figure 4c) than after demoulding (Figure 3c). On the contrary, the sandblasting was less helpful with concrete demoulded with POM because the open porosity was already present after demoulding. FT-IR analyses of concrete sides were performed after peeling but only residues of coating were detected on these concrete sides (whatever the nature of mould used). The debonding occurred inside the layer of the PU coating if the substrate had been sandblasted before the deposition of the coating.

\section{Conclusion}

A specific methodology of $90^{\circ}$-peel test was used to measure the fracture energy between concrete and PU coating. By introducing a porous and thin membrane to strengthen the layer of coating, measurements were reproducible and allowed comparing the fracture energies with the FT-IR analyses of the loci of failure recorded after debonding. These results were correlated to the surface properties of the reference concrete surface after demoulding (topography, composition, roughness) that were characterized by several methods. The influence of the nature of mould was significant. Some moulds, such as POM, could induce a micro-tearing of the extreme surface of concrete during the demoulding. This phenomenon increased the roughness (and the open porosity) of concrete and improved the anchorage of the liquid coating (before its crosslinking). On the contrary, the smooth and flat concrete surface induced after using a PVC mould did not allow a good adhesion of PU coating. The influence of the mechanical anchorage was confirmed by the high fracture energies measured on the sandblasted samples of concrete. In future, analyses of the surface porosity and sorptivity will be performed to confirm these results.

\section{References}

[1] Dubosc, A., Escadeillas, G. \& Blanc, P.J., Characterization of biolical stains on external concrete walls and influence of concrete ad underlying material. Cement and Concrete Research, 31, pp. 1613-1617, 2001.

[2] Manoudis, P.N., Karapanagiotis, I., Tsakalof, A., Zuburtikutis, I., Kolinkeova, B. \& Panayiotou, C., Surface properties of superhydrophobic coatings for stone protection. Journal of Nano Research, 8, pp. 23-33, 2009.

[3] Chattopadhyay, D.K. \& Raju, K.V.S.N., Structural engineering of polyurethane coatings for high performance applications. Progress in Polymer Science, 32, pp. 352-418, 2007. 
[4] Carmona-Quiroga, P.M., Martínez-Ramírez, S., Sobrados, I. \& BlancoVarela, M.T., Interaction between two anti-graffiti treatments and cement mortar (paste). Cement and Concrete Research, 40, pp. 723-740, 2010.

[5] Barquins, M. \& Ciccotti, M., On the kinetics of peeling of an adhesive tape under a constant imposed load. International Journal Adhesion and Adhesives, 17, pp. 65-68, 1997.

[6] Horgnies, M., Darque-Ceretti, E. \& Combarieu, R., Adhesion of pressure sensitive adhesives to automotive coatings: Influence of topcoat composition. Journal of Adhesion Science and Technology, 18, pp. 10471061, 2004.

[7] Johnson, K.L., Kendall, K. \& Roberts, A.D., Surface Energy and the contact of elastic solids. Proceedings of Royal Society of London, 324, pp. 301-313, 1971.

[8] Kinloch, A.J., Adhesion and adhesives: science and technology. Chapman and Hall, London, New York, pp. 66-73, 1987.

[9] Giannis, S., Adams, R.D., Clark, L.J. \& Taylor, M.A., The use of a modified peel specimen to assess the peel resistance of aircraft fuel tank sealants. International Journal of Adhesion and Adhesives, 28, pp. 158-175, 2008.

[10] Almeida, E., Balmayore, M. \& Santos, T., Some relevant aspects of the use of FT-IR associated techniques in the study of surfaces and coatings. Progress in Organic Coatings, 44, pp. 233-242, 2002.

[11] Poliskie, M. \& Clevenger, J.O., Fourier Transform Infrared (FT-IR) spectroscopy for coating characterization and failure analysis. Organic Finishing, pp. 44-47, 2008.

[12] Chollet, M., Horgnies, M., Analyses of the surfaces of concrete by Raman and FT-IR spectroscopies: comparative study of hardened samples after demoulding and after organic post-treatment. Surface and Interface Analysis, In press.

[13] Agrawal, R.K. \& Drzal, L.T., Adhesion mechanisms of polyurethanes to glass surfaces. Part I. Structure property relationships in polyurethanes and their effects on adhesion to glass. Journal of Adhesion, 54, pp. 79-102, 1995.

[14] Kendall, K., Thin-film peeling - the elastic term. Journal of Physics D: Applied Physics, 8, pp. 1449-1452, 1975.

[15] Frost, R.L., Cejka, J. \& Weier, M.L., Molecular structure of the uranyl silicates - a Raman spectroscopic study. Journal of Raman spectroscopy, 37, pp. 538-551, 2005.

[16] Daniel-da-Silva, A.L., Bordado, J.C.M. \& Martin-Martinez, J.M., Moisture curing kinetics of isocyanate ended urethane quasi-prepolymers monitored by IR spectroscopy and DSC. Journal of Applied Polymer Science, 107, pp. 700-709, 2007.

[17] Agrawal, K. \& Drzal, L., Adhesion mechanisms of polyurethanes to glass surfaces. Journal of Adhesion Sciences Technology, 9, pp. 1381-1400, 1995. 